Table 1. Description of study population

\begin{tabular}{|c|c|c|c|c|c|c|c|c|}
\hline & \multicolumn{2}{|l|}{ LN } & \multicolumn{4}{|l|}{ RA } & & \\
\hline & \multirow[b]{2}{*}{$\mathrm{N}$} & \multirow[b]{2}{*}{$\%$} & \multirow[b]{2}{*}{$\mathrm{N}$} & \multirow[b]{2}{*}{$\%$} & \multicolumn{2}{|c|}{ tDMARDs } & \multicolumn{2}{|c|}{ Non tDMARDs } \\
\hline & & & & & $\mathrm{N}$ & $\%$ & $\mathrm{~N}$ & $\%$ \\
\hline \multicolumn{9}{|l|}{ Age (years) } \\
\hline $18-34$ & 1700 & 26.6 & 9015 & 8.3 & 1828 & 11.1 & 7187 & 7.8 \\
\hline $35-44$ & 1743 & 27.2 & 16662 & 15.4 & 2816 & 17.1 & 13846 & 15.1 \\
\hline $45-54$ & 1563 & 24.4 & 29955 & 27.7 & 4452 & 27.1 & 25503 & 27.8 \\
\hline $55-64$ & 1397 & 21.8 & 52685 & 48.6 & 7354 & 44.7 & 45331 & 49.3 \\
\hline \multicolumn{9}{|l|}{ Gender } \\
\hline Female & 5385 & 84.1 & 78419 & 72.4 & 12653 & 76.9 & 65766 & 71.6 \\
\hline Male & 1018 & 15.9 & 29898 & 27.6 & 3797 & 23.1 & 26101 & 28.4 \\
\hline
\end{tabular}

Table 2. IRs per $1,000 \mathrm{PY}[95 \% \mathrm{Cl}]$ of $\mathrm{SI}$ for $\mathrm{LN}$ and RA patients

\begin{tabular}{lcccc}
\hline & $\begin{array}{c}\text { LN total PY } \\
22065\end{array}$ & $\begin{array}{c}\text { RA total PY } \\
365033\end{array}$ & & \\
& & & tDMARDs & Non tDMARDs \\
\hline & & & total PY $=60999$ & total PY $=$ \\
& & & 304034 \\
\hline Pneumocystis carini & $28.2[26.0-30.4]$ & $8.5[8.2-8.8]$ & $12.6[11.7-13.5]$ & $7.7[7.4-8.0]$ \\
pneumonia & & & & \\
Septicaemia & $23.3[21.3-25.3]$ & $12.1[11.7-12.4]$ & $13.3[12.3-14.2]$ & $11.8[11.5-12.2]$ \\
Cytomegalovirus & $13.4[11.9-14.9]$ & $4.4[4.2-4.6]$ & $6.2[5.6-6.8]$ & $4.1[3.8-4.3]$ \\
infection & & & & \\
Tuberculosis & $7.2[6.0-8.3]$ & $6.7[6.5-7.0]$ & $18.2[17.1-19.3]$ & $4.4[4.2-4.7]$ \\
Mycosis & $5.1[4.1-6.0]$ & $2.7[2.6-2.9]$ & $4.6[4.1-5.1]$ & $2.4[2.2-2.5]$ \\
Aspergillosis & $4.7[3.8-5.6]$ & $2.7[2.5-2.9]$ & $2.1[1.7-2.5]$ & $2.8[2.6-3.0]$ \\
Herpes & $3.3[2.5-4.0]$ & $2.4[2.2-2.6]$ & $2.9[2.5-3.3]$ & $2.3[2.1-2.5]$ \\
\hline
\end{tabular}

Disclosure of Interests: Mariko Nio Employee of: Chugai Pharmaceutical Co., Ltd., Kosei Tajima Employee of: Chugai Pharmaceutical Co., Ltd., Naofumi Sugaya Employee of: Chugai Pharmaceutical Co., Ltd., Tomoyuki Ishiwata Employee of: Chugai Pharmaceutical Co., Ltd., Tatsuhiko Iwase Employee of: Chugai Pharmaceutical Co., Ltd., hiroyuki kato Employee of: Chugai Pharmaceutical Co., Ltd., Misato Hashizume Employee of: Chugai Pharmaceutical Co., Ltd. DOI: 10.1136/annrheumdis-2020-eular.1199

\section{AB0436 CHANGES OF LYMPHOCYTE SUBSETS AND CLINICAL INDEXES IN PERIPHERAL BLOOD OF PATIENTS WITH ANTI-PHOSPHOLIPID SYNDROME}

W. Niu ${ }^{1}$, H. Y. Wen ${ }^{1}{ }^{1}$ The Second Hospital of Shanxi Medical University, Rheumatology and Immunology Department, Taiyuan Shanxi, China

Background: Anti-phospholipid Syndrome (APS) is a non-inflammatory autoimmune disease, which can be divided into primary and secondary. Changes in lymphocyte numbers in APS are caused by disruption of the immune balance. Objectives: The levels of lymphocyte subsets in peripheral blood of patients with anti-phospholipid syndrome were observed and their clinical indexes were analyzed. Methods: 53 patients with anti-phospholipid syndrome (APS) were collected as the case group and divided into two groups of $A, B$ according to whether primary and 50 health examiners as the healthy control group. The levels of peripheral lymphocyte subsets and laboratory data [erythrocyte sedimentation rate (ESR),

Table 1. Comparison of clinical data of two case groups and healthy control group M (p25, p75)

\begin{tabular}{lcccc}
\hline Groups & Case group A & Case group B & $\begin{array}{c}\text { Healthy control } \\
\text { group }\end{array}$ & $\begin{array}{c}\mathrm{H} \\
\text { value }\end{array}$ \\
$\begin{array}{l}\text { History of } \\
\text { thrombus } \\
\text { (case) }\end{array}$ & $4^{\mathrm{a}}$ & $8^{\mathrm{a}}$ & - & 13.7090 .001 \\
$\begin{array}{l}\text { History of } \\
\text { adverse } \\
\text { pregnancy } \\
\text { (case) }\end{array}$ & $3^{\mathrm{a}}$ & & & \\
ESR & & $19^{\mathrm{a}}$ & - & $34.596<0.001$ \\
& 20.00 & & & \\
CRP & $(12.25,111.00)^{\mathrm{a}}$ & $(14.25,95.00)^{\mathrm{a}}$ & $(6.00,13.00)$ & $34.381<0.001$ \\
PLT & 15.00 & 7.33 & 2.10 & $35.263<0.001$ \\
& $(4.03,37.83)^{\mathrm{ab}}$ & $(1.76,21.13)^{\mathrm{ab}}$ & $(1.28,2.31)$ & \\
& 228.00 & 197.00 & 258.50 & $33.482<0.001$ \\
& $(189.50,573.25)^{\mathrm{ab}}$ & $(66.00,260.50)^{\mathrm{ab}}$ & $(228.25,272.25)$ & \\
\hline
\end{tabular}

Note: ${ }^{\mathrm{a} C o m p a r i s o n}$ with healthy control group $P<0.05$; ${ }^{\mathrm{b}}$ Comparison with case group $P<0.05$.
Table 2. Comparison of lymphocyte subsets in peripheral blood of two case groups and healthy control group M (p25, p75)

\begin{tabular}{lcccc}
\hline Groups & $\mathrm{T}(\mathrm{ng} / \mathrm{ml})$ & $\mathrm{CD} 4^{+} \mathrm{T}(\mathrm{ng} / \mathrm{ml})$ & $\mathrm{CD}^{+} \mathrm{T}(\mathrm{ng} / \mathrm{ml})$ & $\mathrm{CD}^{+} \mathrm{T} / \mathrm{CD} 8^{+} \mathrm{T}$ \\
\hline Case & 1140.22 & 606.18 & 494.55 & 1.56 \\
group A & $(878.86,1819.56)^{\mathrm{ab}}$ & $(473.50,873.45)^{\mathrm{b}}$ & $\left(252.90,1022.24^{\mathrm{b}}\right.$ & $(0.75,2.52)^{\mathrm{a}}$ \\
Case & 664.89 & 383.64 & 220.19 & 1.53 \\
group B & $(281.36,1360.00)^{\mathrm{ab}}$ & $(142.46,678.25)^{\mathrm{ab}}$ & $(114.43,464.50)^{\mathrm{ab}}$ & $(0.94,3.07)^{\mathrm{a}}$ \\
Healthy & 1250.50 & 639.00 & 422.00 & 1.55 \\
$\quad$ control & $(1070.00,1576.50)$ & $(543.00,787.50)$ & $(333.25,526.50)$ & $(1.24,2.04)$ \\
group & & & & \\
$H$ value & 11.444 & 14.704 & 6.498 & 18.607 \\
$P$ value & 0.003 & 0.001 & 0.039 & $<0.001$ \\
Groups & $\mathrm{Th2}$ & $\mathrm{Th17}(\mathrm{ng} / \mathrm{ml})$ & $\mathrm{Treg}(\mathrm{ng} / \mathrm{ml})$ & $\mathrm{Th} 17 / \mathrm{Treg}$ \\
Case & 10.26 & 7.07 & 21.98 & 0.33 \\
$\quad$ group A & $(7.36,14.72)$ & $(3.65,12.17)$ & $(18.00,34.25)$ & $(0.12,0.48)$ \\
Case & 2.78 & 7.20 & 20.29 & 0.31 \\
group B & $(1.22,3.56)^{\mathrm{a}}$ & $(3.29,10.50)$ & $(13.03,31.31)^{\mathrm{a}}$ & $(0.25,0.38)$ \\
Healthy & 10.80 & 5.45 & 29.09 & 0.18 \\
$\quad$ control & $(5.39,15.83)$ & $(4.06,7.56)$ & $(21.63,42.07)$ & $(0.13,0.33)$ \\
group & & & & \\
$H$ value & 10.884 & 2.452 & 7.516 & 2.590 \\
$P$ value & 0.004 & 0.293 & 0.023 & 0.274 \\
\hline
\end{tabular}

Note: ${ }^{\mathrm{a} C o m p a r i s o n}$ with healthy control group $P<0.05$; ${ }^{\mathrm{b}}$ Comparison with case group $P<0.05$

C-reactive protein (CRP), platelets (PLT)]levels in the three groups were analyzed. The measurement data is not subject to normal distribution using the Median-Quartile method for statistical description; multiple sample comparisons using the Kruskal-Wallis $\mathrm{H}$ test; $\mathrm{p}<0.05$ as the difference is statistically significant.

Results: (1) The rates of thrombosis and adverse pregnancy in the two case groups were significantly increased. In the two case groups, the ESR and CRP were higher than those in the healthy control group, and the CRP in group A was higher. (2) Compared with the healthy control group, the levels of $\mathrm{CD}^{+} \mathrm{T}, \mathrm{CD} 4^{+} \mathrm{T} / \mathrm{CD} 8^{+} \mathrm{T}$ in case $\mathrm{A}$ group were increased, while the levels of total T,CD4 ${ }^{+} \mathrm{T}, \mathrm{CD} 8^{+} \mathrm{T}, \mathrm{CD} 4^{+} \mathrm{T} / \mathrm{CD} 8^{+} \mathrm{T}$, Th2 and Treg cells were decreased. However,there was no significant difference in Th17 cells level and Th17/Treg ratio compared with the healthy control group.

Conclusion: APS patients were more prone to have thrombosis, adverse pregnancy and thrombocytopenia. The changes of lymphocyte subsets were seen in peripheral blood, and the primary and secondary had different directions and different degrees of manifestation.However, whether the secondary factors can aggravate the clinical indicators of APS is still unclear.

References:

[1] Simonin Laurent,Pasquier Elisabeth,Leroyer Christophe et al. Lymphocyte Disturbances in Primary Antiphospholipid Syndrome and Application to Venous Thromboembolism Follow-Up.[J].Clin Rev Allergy Immunol, 2017, 53: 14-27.doi:10.1007/s12016-016-8568-1.

Disclosure of Interests: None declared

DOI: 10.1136/annrheumdis-2020-eular.5167

\section{$\mathrm{AB} 0437$ \\ RISK FACTORS ASESSMENT FOR SUBCLINICAL ARTHEROSCLEROSIS IN PRIMARY SJÖGREN'S SYNDROME.}

M. Novella-Navarro ${ }^{1}$, J. L. Cabrera-Alarcón ${ }^{2}$, J. L. Rosales ${ }^{3}$, J. J. González Martin ${ }^{4}$, P. García de la Peña ${ }^{4}$, O. Carrion ${ }^{5} .{ }^{1}$ Hospital Universitario La Paz, Rheumatology, Madrid, Spain; ${ }^{2}$ Centro Nacional Investigaciones Cardiovasculares (CNIC), Madrid, Spain; ${ }^{3}$ Hospiten Rambla, Rheumatology, Santa Cruz de Tenerife, Spain; ${ }^{4}$ Hospital Universitario Sanchinarro, Rheumatology, Madrid, Spain; ${ }^{5}$ Hospital Universitario Sanchinarro, Vascular Surgery, Madrid, Spain

Background: Some autoimmune diseases, including rheumatoid arthritis (RA) and systemic lupus erythematosus (SLE), are considered to be independent risk factors for vascular morbidity and mortality. These pathologies present accelerated atherosclerosis, partly because of a chronic sustained inflammation, greater prevalence of cardiovascular risk factors (CVRFs) and pharmacological therapy. However, regarding primary Sjögren's syndrome (pSS), available data are heterogeneous and proceed from small case series. For this reason, the aim of this study was to provide further information on the identification of atherosclerosis in pSS and its possible association with clinical and analytical parameters of the disease.

Objectives: To assess presence of subclinical atherosclerosis by means of carotid ultrasound in patients with pSS and to analyze clinical, analytical and CVRF along with their potential association with the presence of subclinical cardiovascular affectation. Methods: This is a cross-sectional study of 38 patients with pSS (all patients met ACR/EULAR ${ }^{1}$ classification criteria for $\mathrm{pSS}$ ) and 38 age and sex matched controls. Demographic variables and classical CVRFs were collected (Hypertension, Diabetes mellitus, dyslipemia, Body Mass Index and smoking habit) and the presence of subclinical atherosclerosis was assessed by carotid ultrasound with carotid intima-media thickness (CIMT) measurement and determination of the presence of atheromatous plaques ${ }^{2}$, both in pSS patients and controls. Disease 
features were also collected in pSS patients (disease duration, disease activity measured by ESSDAI, glandular vs extraglandular involvement, serological features and treatments received)

Statistical analysis: To evaluate differences between patients and controls, T-test or Wilcoxon test with continuity correction, were used for quantitative features and Fisher test for categorical variables. In order to test the presence of pSS as an independent risk factor for subclinical atherosclerosis, from other features as classic CVRFs or analytical data, first we adjusted logistic binomial regression in a bivariate analysis, to select possible predictors to be included in a multivariate analysis. Statistical significance was $\mathrm{p}<0.05$, and $\mathrm{OR} \mathrm{Cl} 95 \%$ vas calculated. $R$-Statistics v- 3.6

Results: All of the 76 patients included were women, with a mean age of 53.7 \pm 11.7 years. For both groups, no differences between prevalence of classical CVRFs were found. Subclinical atherosclerosis presence was higher in patients with pSS than in controls [OR $=4.17,95 \% \mathrm{Cl}(1.27-16.54), \mathrm{p}<0.001]$, as well as CIMT values $(0.79 \pm 0.43 \mathrm{~mm}$ vs. $0.66 \pm 0.27 \mathrm{~mm} ; \mathrm{p}=0.02)$. An association of subclinical atherosclerosis with erythrocyte sedimentation rate $[\mathrm{OR}=1.18,95 \% \mathrm{Cl}$ $(1.05-1.37), p<0.05]$ and Rheumatoid Factor $[\mathrm{OR}=1.28,95 \% \mathrm{Cl}(1.63-2.26)$ $\mathrm{p}<0.05]$.

Conclusion: This cohort showed a greater prevalence of subclinical atherosclerosis in patients with pSS, indicating this disease as an independent risk factor for presence of early vascular damage.

References:

[1] Vitali C et al. Classification Criteria for Sjögren Syndrome: a revised version of the European criteria proposed by the American-European Consensous Group. Ann Rheum Dis. 2002; 61: 554-8

[2] Touboul PJ et al. Mannheim carotid intima-media thickness and plaque consensus (2004-2006-2011). An update on behalf of the advisory board of the 3rd, 4th and 5th watching the risk symposia, at the 13th, 15th and 20th European Stroke Conferences, Mannheim, Germany, 2004, Brussels, Belgium, 2006, and Hamburg, Germany, 2011. Cerebrovasc Dis. 2012; 34 : 290-6

Disclosure of Interests: Marta Novella-Navarro: None declared, José Luis Cabrera-Alarcón: None declared, José Luis Rosales Grant/research support from: I have received financial support from Novartis, UCB, Pfizer, Abvie to meeting and symposia, Jorge Juan González Martin Grant/research support from: I have received finacial grants from Novartis, Lilly, Pfizer, Abvie for meetings and symposia assistance, Paloma García de la Peña Grant/research support from: I have received finacial grants from Novartis, Lilly, Pfizer, Abvie for meetings and symposia assistance, Ofelia Carrion: None declared

DOI: 10.1136/annrheumdis-2020-eular.989

\section{AB0438 MALIGNANCIES IN PATIENTS WITH PRIMARY SJOGREN'S SYNDROME}

Ö. Özdemir Ișık ${ }^{1}$, A. Yazici ${ }^{1}$, A. Cefle ${ }^{1} .{ }^{1}$ Kocaeli University School of Medicine, Rheumatology, Kocaeli, Turkey

Background: Sjogren's syndrome (SS) is a chronic, systemic, autoimmune disease. The risk of developing lymphoproliferative malignancies is high in primary Sjogren's syndrome(pSS).

Objectives: In this study, we planned to present malignancy data in patients who were followed up in our outpatient clinic with a diagnosis of pSS.

Methods: Data of 151 patients diagnosed with pSS between 2004-2019 were retrospectively reviewed and clinical, demographic characteristics of 15 patients diagnosed with malignancy were examined.

Results: All 15 patients with malignancy were female, their mean age was $59 \pm$ 13 years, and the disease duration was $9 \pm 1$ years.

In this group, $7 \%$ of the patients had fever, $13 \%$ had weight loss and $7 \%$ had night sweats. Dry eye was present in $87 \%$, dry mouth in $93 \%$, LAP in $53 \%$ (Table 1). None of the patients had myositis, neuropathy and vasculitis. In $87 \%$ of the patients, schirmer was below $5 \mathrm{~mm}$ and in $67 \%$ of the salivary gland scintigraphy, decreased involvement in the parotid and submandibular gland was detected. Salivary gland biopsy was compatible with pSS diagnosis in $53 \%$ of patients. Rheumatoid factor, ANA, SS-A and SS-B were positive in $\% 60, \% 93$, $\% 67$ and $\% 53$ of patients, respectively.

Table 1. The data of pSS patients with malignancy

$\begin{array}{lr}\text { Gender (Female) } & \mathrm{N}(\%) \\ \text { Dry mouth } & 15(100) \\ \text { Dry Eye } & 14(93) \\ \text { Arthritis } & 13(87) \\ \text { Parotitits } & 3(20) \\ \text { Raynaud Phenomenon } & 4(27) \\ \text { Lymphadenopathy } & 2(13) \\ \text { Interstitial Lung Disease } & 8(53) \\ \text { Smoking } & 4(27) \\ \end{array}$

Table 1. The data of pSS patients with malignancy

\begin{tabular}{lc}
\hline Hypocomplementemia & $4(27)$ \\
Malignancy & $2(13)$ \\
Lung Cancer & $4(27)$ \\
Breast Cancer & $3(20)$ \\
Thyroid Papillary Cancer & $2(13)$ \\
Cervical Cancer & $1(7)$ \\
Vulva Cancer & $1(7)$ \\
Mycosis Fungoides & $1(7)$ \\
MALT lymphoma & $1(7)$
\end{tabular}

Low C3 level was detected in $27 \%$ of patients and C4 level was normal in all patients. Hypergammaglobulinemia was detected in $\% 27$ patents but data of five patients could not be reached. Malignancy was detected in $10 \%$ of the patients who were followed up with the diagnosis of PSS. Two patients had cervical cancer (CA), four had breast $C A$, three had thyroid papillary $C A$, one had diffuse large b cell lymphoma, one had MALT (mucous-associated lymphoid tissue) lymphoma, one had mycosis fungoides, one had vulva epithelia carcinoma and two had lung CA. Patients with malignancy and those without were compared in terms of clinical and laboratory findings. There was a significant relationship between presence LAP and smoking with development of malignancy. Subgroup analysis was performed according to titers of C-Reactive protein (CRP) and erythrocyte sedimentation rates (ESH), but there was no significant relationship between laboratory findings and the development of malignancy. (Table 2)

Conclusion: According to 2015 data of Turkey unified database for all age groups, the rate of cancer in woman is $25 \%$ for breast cancer, $12 \%$ for thyroid CA, $5.1 \%$ for lung CA, 2.5\% for cervical CA, 2.8\% for non-hodgkin lymphoma. Patients with pSS have a 6 to 19-fold increased risk for the development of non-Hodgkin B-cell lymphoma. For these reasons, detailed questioning and physical examination gain importance in the follow-up of patients

References:

[1] E Theander, G Henriksson, O Ljungberg.Lymphoma and other malignancies in primary Sjögren's syndrome: a cohort study on cancer incidence and lymphoma predictors. Ann Rheum Dis. 65 (6):796-803 2006

Table-2. Relationship between presence of malignancy and clinical and laboratory findings

\begin{tabular}{lccccc}
\hline N(\%) & $\begin{array}{c}\text { Malignancy( } \\
\mathbf{1 5}\end{array}$ & $\begin{array}{c}\text { Malignancy(-) } \\
\mathbf{1 3 6}\end{array}$ & $P$ & OR & $\% 95 \mathrm{Cl}$ \\
& & & & & \\
\hline Hypocomplementemia & $4(27)$ & $11 / 96(12)$ & 0,119 & 2,81 & $0,76-10,3$ \\
Fever & $1(7)$ & $7(5)$ & 0,576 & 1,31 & $0,15-11,4$ \\
Night Sweats & $1(7)$ & 0 & $\star$ & $*$ & $*$ \\
Weight Loss & $2(13)$ & $10(7)$ & 0,339 & 1,93 & $0,38-9,81$ \\
Smoking & $7(47)$ & $24(20)$ & 0,043 & 3,6 & $1,19-10,9$ \\
LAP & $8(53)$ & $36(27)$ & 0,039 & 3,17 & $1,07-9,38$ \\
Hypergammaglobulinemia & $4 / 10(40)$ & $26 / 86(30)$ & $*$ & $*$ & $*$ \\
ESH>50mm/h & $2(13)$ & $8(6)$ & 0,260 & 2,46 & $0,47-12,8$ \\
CRP>3XNormal & $2(13)$ & $14(10)$ & 0,662 & 1,34 & $0,27-6,56$ \\
& & & & &
\end{tabular}

*No analysis was done because the data was not enough

Disclosure of Interests: None declared

DOI: 10.1136/annrheumdis-2020-eular.2617

\section{AB0439 LUNG FINDINGS IN PATIENTS WITH PRIMARY SJOGREN'S SYNDROME}

Ö. Özdemir Işık ${ }^{1}$, A. Yazici ${ }^{1}$, A. Cefle ${ }^{1} .{ }^{1}$ Kocaeli University School of Medicine, Internal Medicine, Division of Rheumatology, Kocaeli, Turkey

Background: Sjogren's syndrome (SS) is a systemic, autoimmune disease and can affect many organs and systems.

Objectives: In this study, we planned to present the lung findings of primary SS (pSS) patients who are being followed in our outpatient clinic.

Methods: Chest radiographs and thorax CTs of 151 patients who were admitted to the rheumatology outpatient clinic between 2004 and 2017 and diagnosed as pSS according to the classification criteria of the American-European consensus group Sjogren's syndrome were retrospectively scanned.

Results: In our study, $97 \%$ of pSS patients were female and $3 \%$ were male and the mean age was $56 \pm 12$ years, disease duration was $10.5 \pm 5$ years.

It was observed dry eye in $86 \%$ of patients, dry mouth in $88 \%$, parotitis in $17 \%$, arthritis in $29 \%$, vasculitis in $4 \%$, neuropathy in $6 \%$, myositis in $1 \%$, lymphadenopathy in $29 \%$ (LAP), and $20 \%$ of patients had Raynaud phenomenon. In $50 \%$ of the patients, chest radiography was normal, and there were no respiratory complaints. Thorax CT was requested due to suspicious appearance on $50 \%$ chest x-ray. 